\title{
Transboundary Climate Change Effects on the Hydrologic Regime in the Rio Conchos Basin
}

\author{
Eusebio Ingol-Blanco ${ }^{1}$ and Daene C. McKinney ${ }^{2}$ \\ ${ }^{1}$ Center for Research in Water Resources, University of Texas at Austin, Austin, TX 78712; PH \\ (512) 471-0031; FAX (512) 471-0072; email: ingrecurhid@mail.utexas.edu \\ ${ }^{2}$ Center for Research in Water Resources, University of Texas at Austin, Austin, TX 78712; PH \\ (512) 471-5644; FAX (512) 471-0072; email: daene@aol.com
}

\begin{abstract}
This paper presents results about potential effects of climate change on the hydrology and water resources in the Rio Conchos basin, with special emphasis on the transboundary water treaty signed between the US and Mexico in 1944. The Rio Conchos watershed, the main tributary of the lower portion of the bi-national Rio Grande/Bravo basin, is located in Chihuahua State in northern Mexico. The most relevant problem in the basin is the frequent occurrence of long drought periods, such as those that occurred in 1950s, 1960s, and the most recent from 1992 to 2003. Coupled with increased water demand and low irrigation efficiencies, the competition for water resources is high on both sides of the border. This paper reports on part of an assessment of expected climate change impacts in the basin. The methodology includes: 1) developing a model that represents the hydrological behavior of the basin; 2) analyzing downscaled climate data from five General Circulation Models (GCMs), for emission scenarios A2 and A1B; 3) simulating the basin under these climate change scenarios; 4) assessing the impacts of climate change on the hydrology and water resources in the basin; and 5) simulating and evaluating water management scenarios that could be used to adapt to the expected climate impacts in the coming decades. Some results from tasks (1) and (2) are reported here. These indicate a negative trend of precipitation in the area over the next few decades. Consequently, streamflow is projected to be lower by more than $18 \%$ at the basin outlet (Ojinaga station at the confluence with the Rio Grande) for scenario A2. Moreover, seasonal runoff analysis shows that winter and summer flows will be reduced more than $25 \%$ by the end of the century. Trend analysis also indicates negative trends over time. In addition, the change in runoff concentration and periodicity was explored in this research.
\end{abstract}

Key words: Hydrologic Modeling, Streamflow, Climate Change, Adaptation, Rio Conchos

\subsection{INTRODUCTION}

In many river basins in the world, water availability is vulnerable to the potential effects of climate change. The irregular distribution of precipitation in space and time plays an important role in defining the hydrologic features of a basin, being even more complicated if alterations in the hydrologic cycle occur as a consequence of climatic variability. Municipal, agricultural, hydropower production, and environmental water uses can all be affected by alterations of hydrologic processes resulting from climate change. At the global scale, studies indicate that temperature will increase more than $3.0{ }^{\circ} \mathrm{C}$ (under the A2 emission scenario) by the end of the 21st century and precipitation will decrease in lower and mid latitudes by 5-25\%, and increase in high latitudes (IPCC, 2008). Consequently, drought conditions and increased evapotranspiration 
rates are projected in summer for sub-tropical regions, and in low and middle latitudes. The main objective of this research is to assess the impacts of climate change on the hydrology and water resources in the Rio Conchos basin, the main tributary to the Rio Bravo/Grande covered under the 1944 water treaty between Mexico and the US. The Rio Conchos basin is located in the Chihuahua State of Mexico, with a drainage area of about 68,000 $\mathrm{km}^{2}$ and a length of more than $720 \mathrm{~km}$. It contributes about 55\% of the water delivered to the US under the 1944 treaty, more than all the other Mexican tributaries in the agreement. During drought periods, there are serious conflicts and competition for water on both sides of the border, and, as a consequence, Mexico can accumulate important deficits of water delivery to the US. The hydrologic behavior of the basin indicates recurrent periods of water stress, long drought periods, and water pollution.

The methodology used to assess climate change impacts in the Rio Conchos basin includes: (1) modeling the hydrological behavior of the basin using the soil moisture method; (2) analyzing multiple, downscaled General Circulation Model (GCM) outputs under relevant emission scenarios; (3) simulating the response of the basin hydrologic system to the resulting climate change; (4) deriving multi-model ensemble outputs describing the basin response to climate change; (5) assessing climate change impacts on hydrology and water resources in basin and their effect on the 1944 US-Mexico treaty; and (6) simulating and evaluating water management scenarios to help water managers adapt to the climate change effects in the next decades.

In the Rio Conchos basin, under emission scenario A2, GCM results indicate that temperature will increase $2.25{ }^{\circ} \mathrm{C}$ and $4.5^{\circ} \mathrm{C}$, respectively, by the middle and end of this century relative to 1980-1999. Precipitation shows a negative trend over all time periods and is projected to decrease $10-12 \%$, on average, by the end of the century.

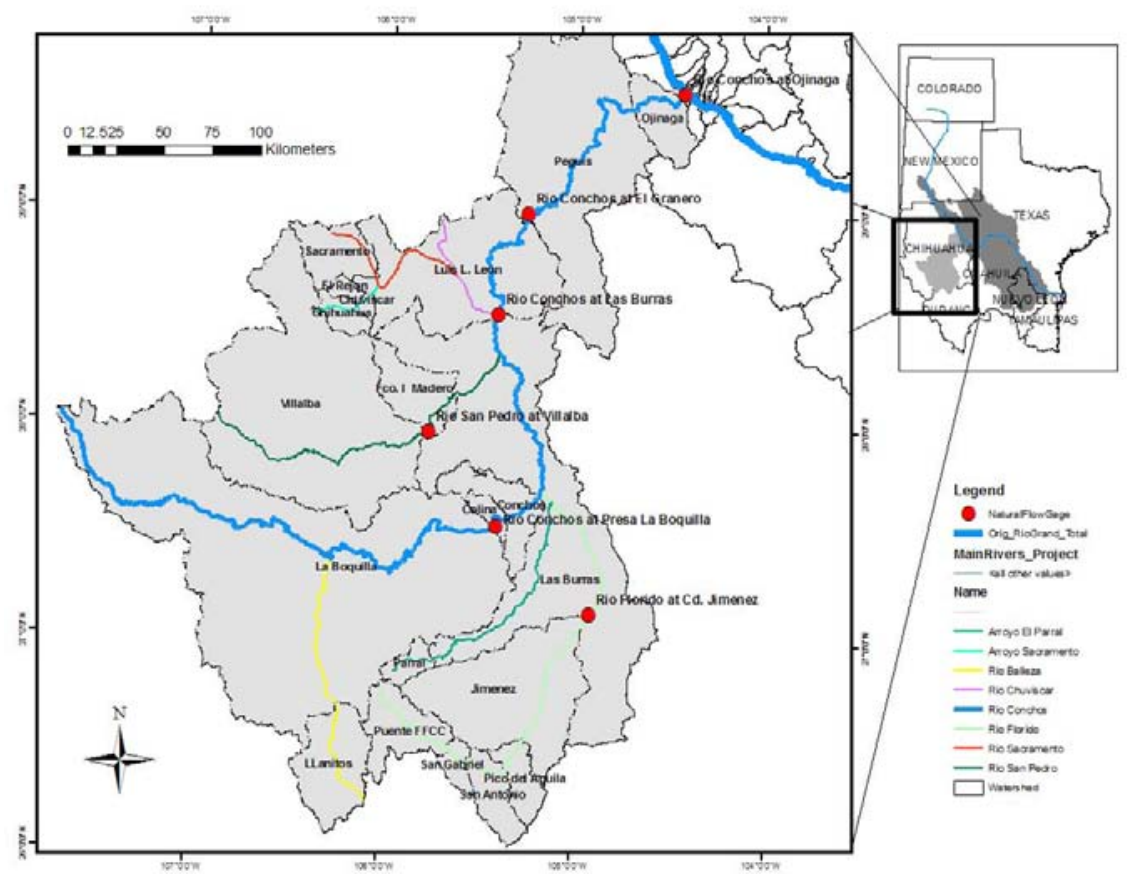

Figure 1. Location of the Rio Conchos basin 


\subsection{METHODOLOGY}

A hydrologic model of the basin was developed in WEAP using climate data and naturalized historic flows for several basin stations. The model was calibrated using the naturalized flows as well as historical flows in which the basin's hydraulic infrastructure is included. Downscaled climate data from five GCMs for emission scenarios A2 (higher emissions path), A1B (middle emissions path), and B1 (lower emission path) were obtained for the Rio Conchos basin (LLNLReclamation-SCU, 2008). Downscaled precipitation and temperature were used as input for the hydrological model to produce streamflow sequences for the different climate scenarios. The results are assessed in terms of water availability and its impact on water users and the 1944 water treaty. Finally, some scenarios of water managements will be simulated and tested in order to propose alternatives for adapting to the climate change impacts on the water system.

\subsection{Climate, land use, and stream flow}

Climate variables such as temperature, precipitation, relative humidity, and wind velocity were obtained from Mexican Institute of Water Technology and the North American Regional Reanalysis (NARR). Data was gathered for a period of twenty years from 1980-1999, several climate stations in the basin were used and consistence analysis was carried out with some of the meteorological variables. The model includes twenty sub-basins with associated soil groups and land use categories (Amato et al., 2006) and the Soil Moisture Method in WEAP was used for hydrologic modeling (Ingol-Blanco and McKinney, 2008). Likewise, naturalized streamflow data from six flow stations (Brandes, 2003) were used in the calibration and validation along with historic streamflows.

\subsection{Hydrological modeling}

The WEAP two layer, soil moisture method is used to simulate the hydrology of the basin (SEI, 2007). The first layer represents the water retained near the surface, which is available to plant roots; the second layer is deeper and water from this layer can be transmitted as base flow or groundwater recharge. The parameters of this model include the root zone conductivity, initial deep storage, and water capacity the water holding capacity of the layers (Ingol-Blanco and McKinney, 2008). The hydrological model for the basin was calibrated using naturalized streamflow for 1980-1999, corresponding to normal hydrologic conditions with peak annual flow produced in August-September. A monthly time step was used for the simulation in each catchment. The model was validated for 1990-1999 a drought period. Both periods were assessed using several statistical parameters (Ingol-Blanco and McKinney, 2009) showing that the WEAP model of the basin reproduces well the hydrologic response of the basin.

\subsection{General Circulation Models and Climate Change Scenarios}

When considering climate change, the first challenge that water resources managers face is deciding what general circulation models (GCMs) should be used for evaluating climate change impacts on water supply? It is not an easy task to answer this question, since GCMs all demonstrate uncertainty in predicting historical climate variables. However, some criteria, e.g., spatial resolution, coupled atmospheric-ocean model, multiple realizations, and advanced modeling, may be taken account in order to reduce uncertainties in water supply forecasts based on GCMs. In addition, selection of emission scenarios that drive GCMs must be selected. Low, middle, and high emission scenarios can be chosen depending on the objective of the study. 
Uncertainties arising from the formulation of emission scenarios (incremental $\mathrm{CO}_{2}$, economic development, population growth, etc.) must be considered.

In this research, outputs from two emission scenarios (A2 and A1B) computed by five GCMs were used to assess climate impacts on the hydrology and water resources in the Rio Conchos basin. The GCMs chosen for this study were: CGCM31 (Canada), CCSM3 (US), ECHAM5 (Germany), MIROC3.2 (Japan), and UKMO-HadCM3 (UK). Statistically downscaled temperature and precipitation from the World Climate Research Programme's (WCRP's) Coupled Model Intercomparrison Project phase 3 (CMIP3) multi-model dataset (LLNLReclamation-SCU, 2008) were used. Emission scenarios A2 and A1B were selected for use here based on the emission paths, high and middle, respectively, as well the fact that they have been applied and discussed in several basins in the world. The future time period considered here is from 2040 - 2099, which is evaluated in 20-year segments (2040 - 2059, 2060 - 2079, and 2080 2099) relative to the period 1980 - 1999.

Stream flows produced by using the downscaled data from the five GCMs form an ensemble response of the basin. The expected response of the basin can be obtained by, at least, two methods: simple averaging and weighted averaging. The weighted method provides increased weight to the GCM that presents less error with respect to historical values. Root Mean Square Error is used to estimate the error.

\subsection{Climate Change Impacts on the Hydrology in the Study Area}

The procedure to evaluate potential climate change impacts on the hydrology of the Rio Conchos basin includes the analysis of changes in precipitation and temperature for the periods mentioned above. Probability density functions (PDFs) and Cumulative Distribution functions (CDFs) were computed to quantify the monthly and annual flows resulting from the simulated climate scenarios. Moreover, changes in annual runoff distribution are evaluated through the Coefficient of Variation (CV), and the stream flow concentration and periodicity (Xie et al., 2005, and Li et al., 2008). Additionally, the non-parametric Mann-Kendall method is used to detect linear trends in annual stream flows (Kahya and Kalayc, 2004).

\subsection{RESULTS}

\subsection{Temperature and Precipitation}

Figure 2 shows the cumulative distribution function for annual precipitation in the Rio Conchos basin for 1980-1999 for the five GCMs and the historical data. Comparisons with historical annual precipitation indicate that the ECHAM5, CGCM31, and MIROC32 GCMs are closer than HadCM3 and CCSM3 models. Although most models simulate well for the lower quartile $(\operatorname{Pr}=$ 0.25), ECHAM5 values are more accurate with respect to historical, more rainfall is simulated by the CCSM3 and CGCM31 models, and less rainfall for the MIROC32 and HadCM3 models, with difference ranging from $4 \%$ to $-8 \%$, respectively. For the upper quartile ( $\operatorname{Pr}=0.75$ ), all models project less precipitation, but ECHAM5, CGCM31, and MIROC32 are more accurate; for instance, the averaging the precipitation from these models at the $75^{\text {th }}$ percentile yields 490 $\mathrm{mm}(\mathrm{Pr} \leq 490 \mathrm{~mm}$, is 0.75 ) compared to $525 \mathrm{~mm}$ in the historical data (an error of $6.6 \%$ ), versus $440 \mathrm{~mm}$ for the CCSM3 and HadCM3 models. 


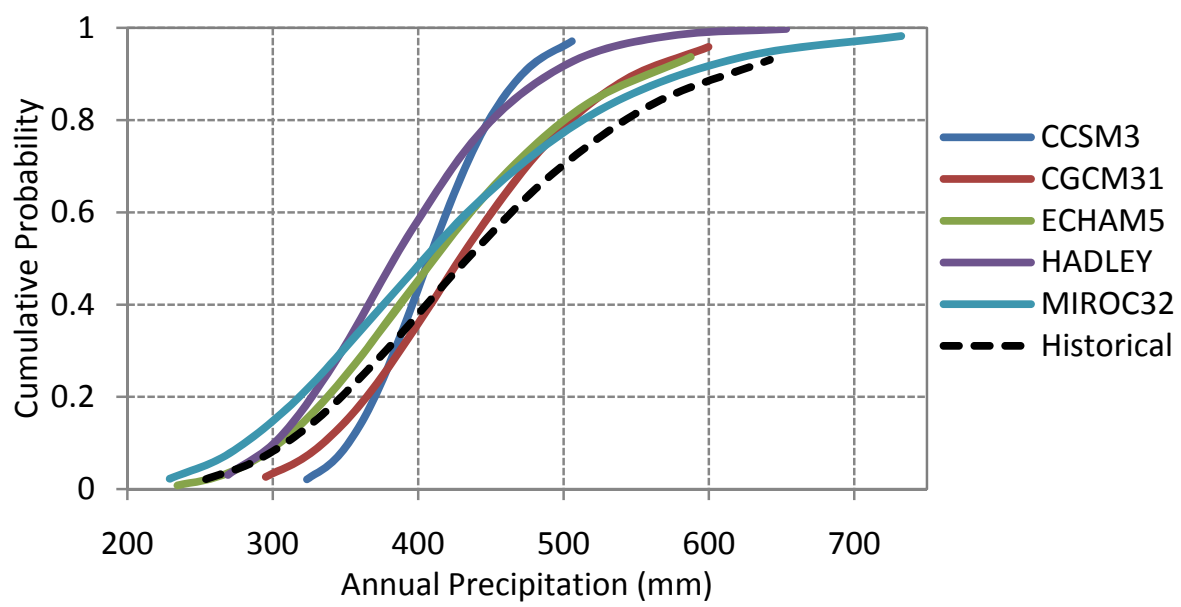

Figure 2. Cumulative distribution function for annual precipitation in the Rio Conchos basin, for 5 GCMs, Scenario A2. Period 1980-1999

Projections for the middle (2040-2059) and end (2080-2099) of this century indicate that the annual temperature will increase $2.25 \mathrm{C}^{0}$ and $4.5 \mathrm{C}^{\circ}$ on average for scenario A2, respectively. Figure 3a shows the annual temperature anomaly for the period 2040-2099 relative to the period 1980-1999, for the five GCMs, including the multi-model ensemble. Temperature shows a positive trend for the whole time period. On the other hand, in Figure 3b, projected precipitation anomalies are computed for the same time period mentioned above. Most of the models do not agree in estimated precipitation, while CCSM3 and HadCM3 show a positive trend, MIROC32, ECHAM31, and CGCM31 show a negative trend during the period. In general terms, the multimodel ensemble indicates a negative trend of precipitation, with a decrease of about $12 \%$ for the end of the century.
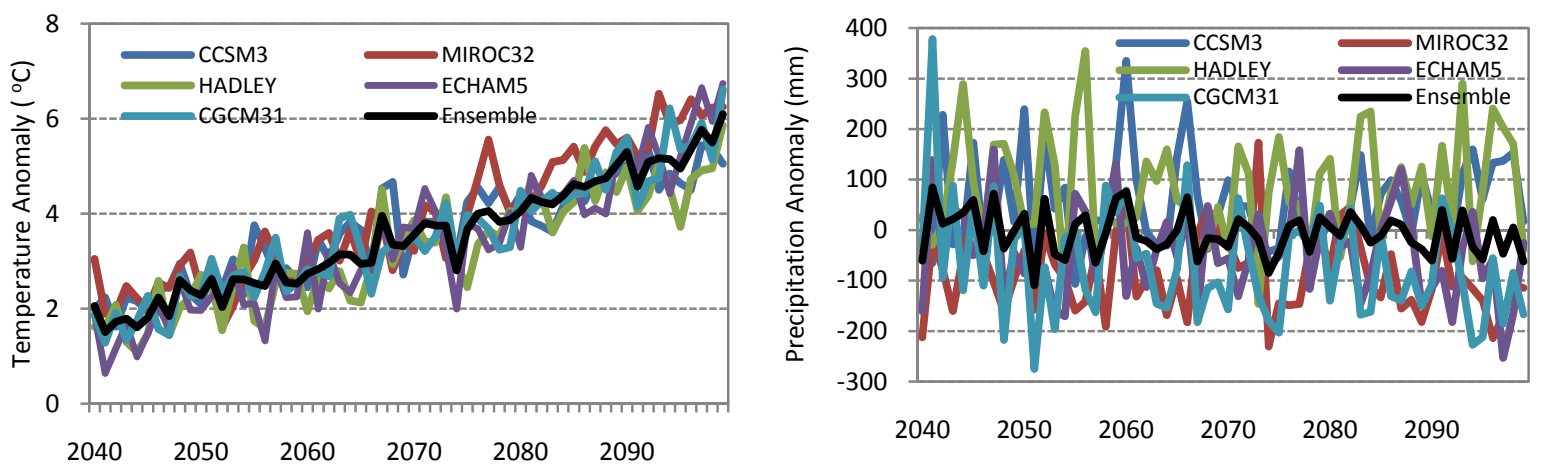

Figure 3. a) Annual temperature anomaly, and b) Annual precipitation anomaly, for emission scenario A2 in the Rio Conchos basin. Period 2040-2099 relative to 1980-1999.

\subsection{Stream flows}

Figure 4 shows the projected annual stream flow variation at Ojinaga (the confluence of the Rio Conchos with the Rio Grande), for five GCMs and multi-model ensemble as well as the relative change of the ensemble for the period 2080-2099. The relative change is between the annual stream flow for each year with respect to the annual historical average for the time period 19801999. Since the basin treaty was signed under historical conditions (up to 1944) for an annual mean flow of $65 \mathrm{~m}^{3} / \mathrm{s}$ at Ojinaga, the relative change gives us an idea of the effect of climate 
change on the water availability in the coming decades. In addition, for the period 2040-2059, higher stream flows are projected by CCSM3 and HadCM3 and less by MIRO32. Relative changes indicate reduction flows around $11 \%$ for the period, with increments during some years, e.g., 2041 and 2056, where the projected stream flow is 20\% above the average. For 2080-2099, the GCMs have similar behavior, and the relative change shows important deficits projected for end of this century, e.g., 2094-2099, and stream flows are projected to be reduced by $18 \%$ for all period (2080-2099).
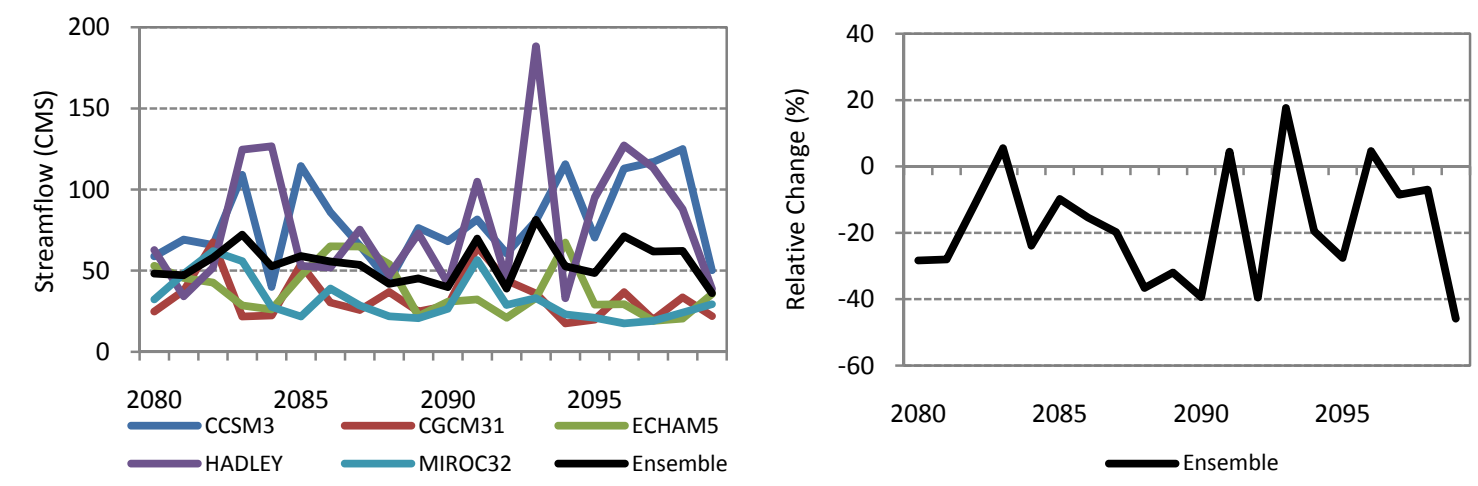

Figure 4. Annual stream flow at Ojinaga. 2080-2099, Scenario A2. a) Annual variation, b) Relative change (\%) for the multi-model ensemble relative to 1980-1999.

Projected monthly stream flows at Ojinaga for the five GCMs and the multi-model ensemble are shown in Figure 5 for the period 2040-2059 and 2080-2099. It should be noted that for 20402059, four GCMs predict the maximum flow in September, and only CCSM3 predicts the peak in August. There are notable differences in magnitude in August and September between MIROC32 predictions and the other models; however, most models predict less water than the historical amount for winter and part of the summer. Comparisons made between the Ensemble and the historical flows indicate important reductions for this time period. For instance, for winter, summer, and part of fall, the monthly stream flow is projected to decrease by more than $20 \%$. Only in September are stream flows expected to increase by more than $15 \%$ on average. For 2080-2099, monthly stream flow is projected to decrease more than $18 \%$ on average. Seasonal variation indicates that winter and summer will be reduced by more than $25 \%$. Increased stream flow is expected for September and October. Most models agree in predicting the peak in September, a month later than that of historical conditions. Projected changes in the circulation patterns of atmosphere and oceans (Mexican Gulf and Pacific Ocean) in the study area could be influencing this behavior.

Dispersion and trend analysis were assessed for annual stream flows at Ojinaga using the Coefficient of Variation (CV) and Mann-Kendall test. Figure 6a shows the CV computed from 2040-2099 (60 years) for five GCMs and the multi-model ensemble. The Ensemble CV ranges from $0.75-2.0$ on average, with most values greater than 1 . This high variability is due to the irregular monthly distribution during the year where the maximum flows in the basin are usually produced in August and September (more than 45\% of the total runoff). The Mann-Kendall statistics (Figure 6b) show a slight negative trend for the whole period, but a small positive trend for 2060-2079. In addition, more uniform annual flows are projected for 2070-2090 for scenario A2 (small differences in $\mathrm{Z}$ values), and stream flows also decrease in this time period. Negative MK statistics mean that the stream flows will decrease with respect to earlier flows; for instance, 
in 2092, the MK statistic is -1.81, indicating a significant negative trend at the $95 \%$ significance level (annual runoff will reduce by $40 \%$ with respect to the previous year).
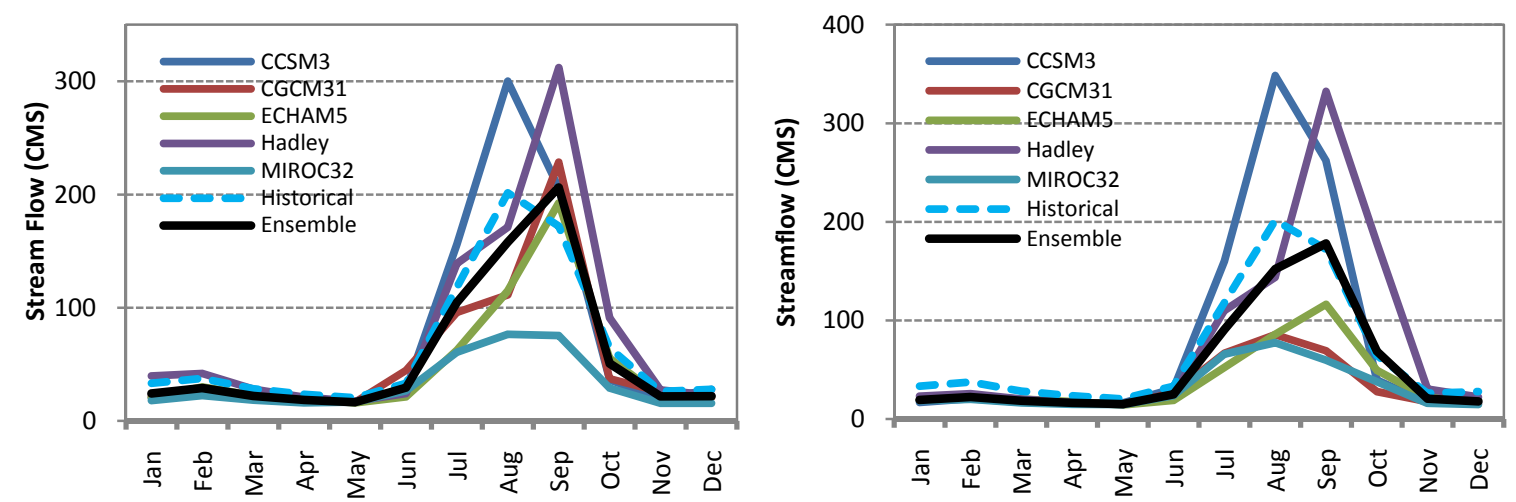

Figure 5. Monthly stream flow at Ojinaga for Scenario A2. a) Period 2040-2059 b) Period 2080-2099
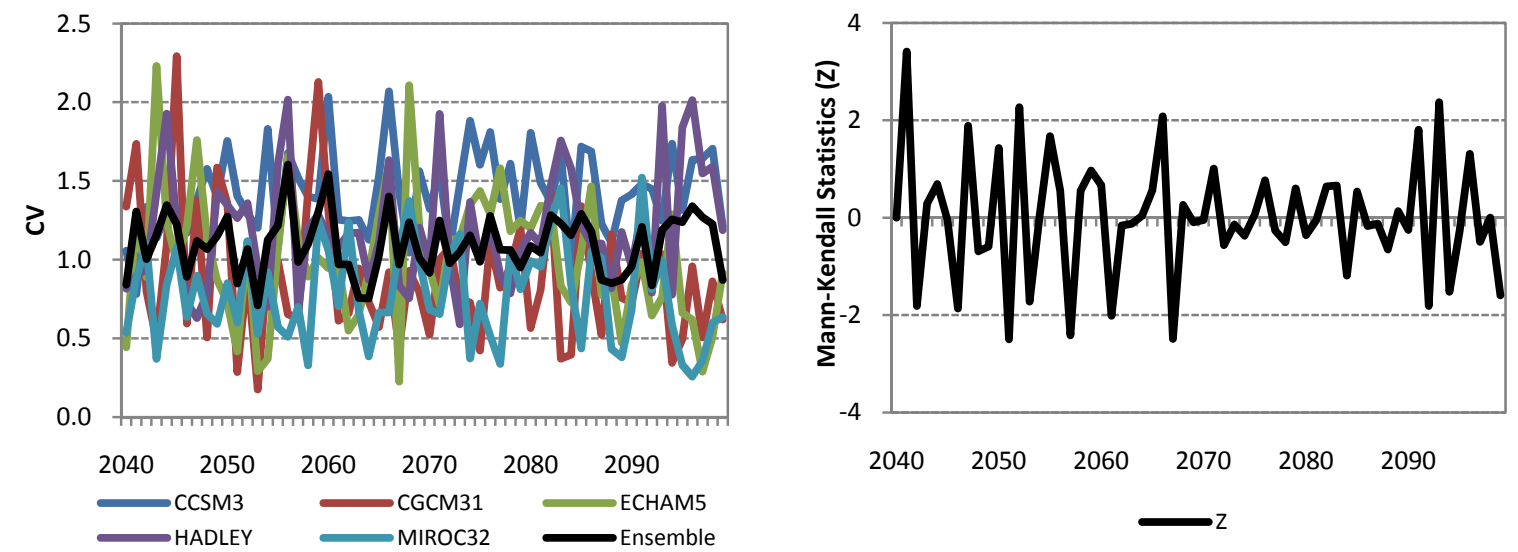

Figure 6. Annual stream flow trend at Ojinaga. a) Coefficient of Variation (CV), b) MannKendall Statistics, for 5 GCMs and the multi-model ensemble.

Change in concentration degree and period was explored to assess the stream flow distribution at Ojinaga station. Concentration degree (CD) can range from 0 to 1 ; a value of 0 indicates that monthly runoff is equal for all months, and a value of 1 indicates runoff in a year will be produced in 1 month. In the multi-model ensemble, CD varies from 0.14-0.46, with an average of 0.29 . Also, a decrease in CD of $7 \%$ is noted for the whole period, from 0.30 for 2040-2059 to 0.28 for 2080-2099. On the other hand, a trend negative in runoff concentration period (CP) is noted, ranging from $0.34^{\circ}$ to $0.17^{\circ}$ on average for 2040-2059 and 2080-2099, respectively, with a rate of the $0.26^{\circ}$ per year which implies that the period of runoff concentration would occur 0.26 days later (per year) in the future. Considering this rate for the 60 years evaluated, the runoff is projected to occur 16 days later in the end of this century. Although, this rate tends to give some evidence about the change of concentration period, a more sophistical method such as Fourier analysis is suggested to evaluate the changes in periodicity of stream flow under potential climate change. 
A cumulative distribution function for the multi-model ensemble of annual flow at Ojinaga was computed for each 20 years (Fig. 7). The projected stream flows are reduced in the period from 2060-2079, with a further increment in the last twenty years of this century. In general, a decrease is evident over the whole period. For the lower quartile $(\operatorname{Pr}=0.25)$, there is a small difference across the time periods, with $\mathrm{Q} \leq 45 \mathrm{~m} / \mathrm{s}$; however, for the upper quartile, the results indicate important differences in the stream flow magnitude. While, the runoff in 2040-2059 is projected to be $\leq 70 \mathrm{~m}^{3} / \mathrm{s}$, it will be reduced to $\mathrm{Q} \leq 57$ and $\mathrm{Q} \leq 61 \mathrm{~m}^{3} / \mathrm{s}$ for 2060-2079 and 20802099 , respectively $(\mathrm{Pr}=0.75)$. This means a reduction of stream flow of $18 \%$ and $13 \%$ with respect to the earlier period. For the median ( $\operatorname{Pr}=0.5)$, runoff is reduced by $11 \%$ and $7 \%$ for the last two periods.

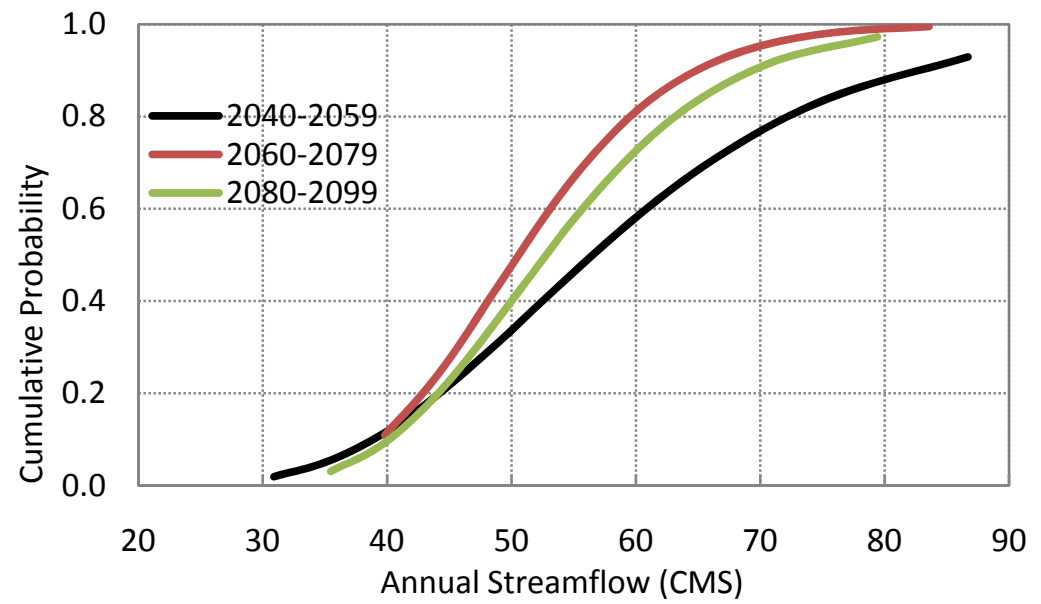

Figure 7. Cumulative distribution function for multi-model ensemble annual stream flow at Ojinaga. Scenario A2.

\subsection{CONCLUSIONS}

Negative effects on stream flow from climate change are projected for the next decades in the Rio Conchos basin; consequently, a negative impact on the 1944 water treaty between the US and Mexico is expected since it was signed under historic hydrological conditions. According to the multi-model ensemble, stream flows are projected to decrease by more than $18 \%$ on average at Ojinaga by the end of this century. Seasonal analysis of runoff indicates that winter and summer will be more restricted in more than $25 \%$ for the end century under scenario A2. A trend analysis performed on the runoff projections also shows negative trends over time. The degree of runoff concentration and periodicity indicate an average concentration degree of 29\%, and a change in concentration period of $0.26^{\circ}$ per year. For the emission scenario A2, results indicate that temperature will increase significantly by the middle and end of this century, relative to 1980-1999. Precipitation shows a negative trend over this period and it is projected to decrease by around $10 \%$ on average, by the end of this century. The analysis shows that annual runoff will decrease more in 2060-2079 than the periods 2040-2059 and 2080-2099, respectively, with most differences in stream flow magnitude located in the inter-quartile range.

\section{References:}

Amato, C. C., McKinney, D.C., Ingol-Blanco, E., and Teasley, R.L. (2006). "WEAP Hydrology model applied: The Rio Conchos Basin”. Center for Research in Water Resources. The University of Texas at Austin. Online Report 06-12. 
Brandes, R.J. (2003). Water availability modeling for the Rio Grande Basin, naturalized stremflow Data. Texas Commission on Environmental Quality. Final Report. Austin.

Ingol-Blanco, E., and D. C. McKinney. (2008). "Hydrologic Model for the Rio Conchos Basin: Calibration and Validation.” Center for Research in Water Resources. The University of Texas at Austin. Online Report 08-9.

Ingol-Blanco, E., and D. C. McKinney. (2009). "Hydrologic Model of the Rio Conchos.” EWRI World Environmental and Water Resources Conference, Kansas City, KS, May 2009.

Intergovernmental Panel on Climate Change (IPCC), 2008: Climate Change and Water. IPCC technical paper VI.

http://www.ipcc.ch/ipccreports/tp-climate-change-water.htm (26 January 2010)

Kahya, E., and S. Kalayl. (2004). "Trend analysis of stream flow in Turkey”. Journal of Hydrology, 289(1-4):128-144.

Li, L., Hao, Z-C., Wang, J-H., Wang, Z-H., and Yu, Z-B. (2008). "Impact of future climate change on runoff in the head region of the Yellow river”. Journal of Hydrologic Engineering, ASCE, Vol. 13, No.5, 347-354.

LLNL-Reclamation-SCU (2008). "Statistically Downscaled WCRP CMIP3 Climate Projections”. Lawrence Livermore National Laboratory-Santa Clara University and Bureau of Reclamation. <http://gdo-dcp.ucllnl.org/downscaled_cmip3_projections/> (24 January 2010)

SEI-Stockholm Environment Institute. (2007). "Water Evaluation and Planning System, WEAP”. Boston.

Xie, Z., Du, Y., Jiang, A., and Ding, Y.(2005). "Climatic trends of different intensity heavy precipitation events concentration in China”. Journal of Geographical Sciences 15, 4 (2005) 459-466 ISSN: 1009-637X. 